Mini Review

\title{
Obstacles facing oocyte cryopreservation in the middle east
}

\section{Abstract}

As of 2013, oocyte cryopreservation has been deemed no longer experimental. It is a routine procedure done in most IVF labs worldwide. Yet in the Middle East it is far from being routine. We take a look at the obstacles facing Oocyte Cryopreservation in the Middle East and possible solutions on how to overcome it.
Volume 7 Issue 2 - 2017

\author{
Mahmoud Samy, Samar Abdelwehab \\ Al Samy Fertility Centre, Egypt
}

Correspondence: Mahmoud Samy, Al Samy Fertility Centre, Mansoura,355II,Egypt, Email suki636@hotmail.com

Received: February 15, 2017 | Published: May 24, 2017

\section{Introduction}

There have been many advances in the science of oocyte cryopreservation. Once thought of as an experimental procedure, today this is no longer the case. Oocyte cryopreservation is done for a wide number of reasons ranging from oocyte donation to fertility preservation. Not only are Oocytes just cryopreserved but Ovarian Tissue as well. The first live birth after ovarian transplant was in 2004 .

Recently a healthy baby boy was delivered to an Arab Muslim woman who had her ovarian tissue cryopreserved during childhood. ${ }^{2}$ This has created more awareness of the possibility of ovarian cryopreservation in the Middle East. Delivery rate with Ovarian Transplant is estimated to be around $24 \%{ }^{3}$

There is no doubt that oocyte cryopreservation and even ovarian tissue is a staple in most IVF centres internationally. Yet in the Middle East we are so very far behind. There are a number of different factors contributing to this detrimental trend.

\section{Current practices}

Currently the majority of IVF laboratories in the Middle East do not routinely freeze oocytes. In Mansoura, Egypt with over ten IVF laboratories in the Delta region, not a single lab regularly freezes eggs. The only times oocyte cryopreservation was done was after oocyte pick up and failure of male partner to show up or very poor quality testicular biopsy. At first we thought this was due to low demand for the procedure. After investigation it was discovered that there was a huge lack of awareness amongst the public and health sector alike on the availability and success of the procedure. However there is an exception in Iran and Lebanon. According to Sunni Islamic Law egg and sperm donation is strictly prohibited. ${ }^{4}$ This explains why most IVF labs in the Middle East don't practice oocyte cryopreservation on a regular basis.

\section{Cancer patients}

With better diagnosis and treatment of cancer today, there is a large number of cancer survivors who will need to avail of this service. In America alone it is estimated that one in thirty people are either undergoing cancer treatment or have done so in the past. Chances of surviving are much better then they were decades ago. ${ }^{5}$ With most patients expecting to have realistic hopes of a normal life. ${ }^{6} \mathrm{I}$ did a quick patient survey done in the Mansoura Oncology Centre (not published), showed that no patients were aware or were even told of the deleterious fertility effect of chemotherapy and radiotherapy.

Due to the distress this survey caused the few patients we interviewed, we then did a quick survey on the oncologists in the centre with surprising results. Over $80 \%$ of doctors were unaware that regional IVF centres were potential providers of the service. Over $90 \%$ doubted the success of oocyte cryopreservation.

When asked if after knowing the availability of gamete cryopreservation they would inform patients in the future. All 30 doctors said no if the patient was pre-pubertal due to the cost and low success rate of patient survival. However they all said they would recommend it of it was done with a lower cost for patient. For post pubertal patients after knowing how the ease and cost effectiveness of semen cryopreservation, they would encourage males to freeze multiple semen samples. For post-pubertal females, $85 \%$ of the oncologists said they wouldn't inform patients, due to the excessive cost and the fact that all of their patients had trouble with the regular day to day costs of living as it is.

\section{Social freezing}

It is no hidden fact that the age of marriage has risen considerably over the last few decades. Traditionally women married young before their twenties or in their early twenties. The following shows the steep decline of girls marrying before they are twenty. ${ }^{7}$ The age of marriage has continued to steadily increase. The increase of higher level educated women and the importance of a career as a source of income in this economically turbulent region has increased the age of marriage and therefore the overall age of first time mothers. Another recent reason for increasing the age of women and marriage in Egypt is the substantially high cost of getting married in the country, which has only been getting higher with the defloatation of the Egyptian Pound. For the first time in Egypt we have seen a considerable increase of women seeking treatment due to Advanced Maternal Age, due to the fact of the time and cost it now takes to get married. Also most men seek older financially secure women to marry to help ease the cost of $\operatorname{living}^{7}$ (Table 1).

\section{Oocyte donation}

Due to religious and legal laws, oocyte donation is strictly prohibited in the region. This is a major factor hindering the widespread practice of oocyte cryopreservation. However the Iranian 
leader Ayatollah Khomeini issued a 'fatwa' allowing egg and sperm donations under specific guidelines. ${ }^{4}$ So in effect Iran and the Lebanon, which are predominately, have a Shiite Muslim population remain the only two countries in the Middle East region, which legally offer egg and sperm donation. However for the rest of the Middle East, relying on ones own gametes remains the only way to conceive. This raises a number of issues for Cancer patients who have gonadal damage due to the cytotoxic nature of their treatment. It also poses a threat to the influx of many women who marry at a much later age then earlier generations.

Table I Decline in Percent of Women Ages I5 to 19 Who Are Married, Selected Arab Countries ${ }^{7}$

\begin{tabular}{lllll}
\hline Country & Year & Percentage \%Women Married under 20 & Year & Percentage \% Women Married under 20 \\
\hline Egypt & 1976 & 22 & 2003 & 10 \\
Tunisia & 1975 & 11 & 2001 & 1 \\
Libya & 1973 & 40 & 1995 & 1 \\
Kuwait & 1970 & 38 & 1996 & 5 \\
Palestine & 1976 & 17 & 2004 & 14 \\
U.A.E. & 1975 & 57 & 2005 & 8 \\
\hline
\end{tabular}

\section{Ovarian tissue cryopreservation for THT}

With great improvement worldwide, many women this century can expect to live a longer life. This means that women may spend one third of their life post-menopausal. MHT (Medical Hormonal Treatment) is one of the main lines of treatment today. Could THT (Tissue Hormonal Treatment) be the way forward? While studies of this lime of treatment are still preliminary, theoretically endogenous production of hormone from ones own cryopreserved ovarian tissue may be more beneficial to women then MHT. Studies first would have to show that the transplanted ovarian tissue could function for at least five years. Cryopreserved Ovarian Tissue can be used to post-pone and alleviate menopausal symptoms. ${ }^{8}$

Endogenous Oestrogen and Progesterone would reduce the sometimes debilitating effects of menopause. Women who have undergone hysterectomies would only need Oestrogen and not Progesterone for endometrial protection. It could also benefit women in many other aspects of their health. Late menopause is associated with a decrease in cardiovascular disease. ${ }^{9}$

If this practice becomes a standard in the future, the Middle East will have to routinely practice Ovarian Tissue Cryopreservation as an influx of patients will demand its practice. Ovarian Tissue Cryopreservation will not be done only for cancer patients seeking fertility preservation but to all women to improve their overall health in old age. As most of these clients will probably be of the higher middle class economic sector, they will seek private clinics and be able to afford the service if offered in our clinics in the Middle East.

\section{Discussion}

With the increase of single women in their thirties and the increase of cancer survivors, there will be an increase of demand for oocyte cryopreservation in the future. The main obstacles facing IVF labs is awareness and social stigma surrounding oocyte cryopreservation. In a recent Egyptian article asking many single women in their thirties, if they would cryopreserve their oocytes to preserve fertility. Many were unaware of the procedure and those who liked the idea cited cost as being the main hindering factor $[10,11]$. In a region where there is low income, things like gamete cryopreservation are seen as a science fiction luxury. Also in a society where there is still very high importance of virginity and an intact hymen until marriage, most oocyte retrievals would have to be done trans-anally or laporoscopically rather then trans-vaginally. Even then, in most rural areas even the knowledge that an unmarried woman underwent a gynecological procedure may greatly reduce her chances of marriage.
The general lack of awareness in the public and health sector remains to be the biggest obstacle. The governments are unwilling to aid in this area, as they have far more pressing issues to deal with like gross unemployment and flailing general healthcare services. In countries were over-population is already an immediate problem, fertility preservation is not high up on the list of priorities. In Mansoura University Fertility Clinic, the IVF lab does not store semen or embryos let alone oocytes or ovarian tissue. One of the main obstacles facing oocyte cryopreservation stems from the IVF laboratories as well. There is a region wide lack of hands on experience with oocyte freezing. It is hardly ever done and most embryologists don't see the need to do it as they can have life long careers without ever having to preform oocyte freezing.

\section{Conclusion}

Oocyte freezing is something done routinely in all labs worldwide. There are still many factors inhibiting its widespread practice in the Middle East. Namely cost and lack of awareness by patients and doctors alike. As this is the first time the Middle East has experienced a steady increase of age in marriage, it is predicted that there will also be an increase in of fertility problems associated with Advanced Maternal Age. Awareness of the limited time women have to conceive may aid social acceptance and practice of social egg freezing. It is worth incorporating oocyte freezing into the training of new embryologists in IVF labs to avoid lack of experience and incompetence when it comes to this procedure.

\section{Acknowledgments}

None.

\section{Conflicts of interest}

None.

\section{References}

1. Donnez J, Dolmans MM, Demylle D, et al. Livebirth after orthotopic transplantation of cryopreserved ovarian tissue. Lancet. 2004;364(9443):1405-1410.

2. Liebenthron J, Dittrich R, Toth B, et al. Orthotopic ovarian tissue transplantation - results in relation to experience of the transplanting centers, overnight tissue transportation and transplantation into the peritoneum. Hum Reprod. 2015;30:i97-i98.

3. Inhorn, Marcia C. Fatwas and ARTs: IVF and Gamete Donation in Sunni v. Shi'a Islam. Journal of Gender, Race and Justice. 2005;9:291-317.

4. Fertility and Sterility®. American Society for Reproductive Medicine, Elsevier Inc, USA, 99(1). 
5. Tonorezos ES, Hudson MM, Edgar AB, et al. Screening and managemen of adverse endocrine outcomes in adult survivors of childhood and adolescent cancer. Lancet Diabetes Endocrinol. 2015;3(7):545-555.

6. Siegel RL, Miller KD, Jemal A. Cancer statistics, 2015. CA Cancer J Clinic. 2015;65(1):5-29.

7. United Nations World Fertility Report 2003, Population Division, DESA, United Nations. 2004

8. Anderson CY, Kirstenson SG, Novel use of ovarian follicular pool to postpone menopause and delay osteoporosis. Reprod. Biomed Online. 2015;31(2):128-131.
9. Jacobsen BK, Heuch I, Kvale G. Age at natural menopause and all cause mortality: a 37 year follow up of 19,731 Norwegian women. Am J Epidemiol. 2003;157(10):923-929.

10. Dina Hashish. Single Egyptian Women over 30; Would you freeze your eggs? Scoop Empire Your Middle East Urban Destination. 2016.

11. Rasha Mansour. She Can Stop Time; I support Egg Freezing 100\%, Scoop Empire Your Middle East Urban Destination. 2016. 